\title{
Cellular Stress Response
}

National Cancer Institute

\section{Source}

National Cancer Institute. Cellular Stress Response. NCI Thesaurus. Code C21067.

Cellular or subcellular processes involved in restoration of a homeostatic condition. 